This item was submitted to Loughborough's Research Repository by the author.

Items in Figshare are protected by copyright, with all rights reserved, unless otherwise indicated.

\title{
New institutional geographies of higher education: the rise of transregional university alliances
}

PLEASE CITE THE PUBLISHED VERSION

https://dx.doi.org/10.1177/0308518X15619175

PUBLISHER

(c) Sage

VERSION

AM (Accepted Manuscript)

\section{PUBLISHER STATEMENT}

This work is made available according to the conditions of the Creative Commons Attribution-NonCommercialNoDerivatives 4.0 International (CC BY-NC-ND 4.0) licence. Full details of this licence are available at: https://creativecommons.org/licenses/by-nc-nd/4.0/

\section{LICENCE}

CC BY-NC-ND 4.0

\section{REPOSITORY RECORD}

Harrison, John, Darren Smith, and Chloe Kinton. 2015. "New Institutional Geographies of Higher Education: The Rise of Transregional University Alliances”. Loughborough University. https://hdl.handle.net/2134/19509. 


\title{
NEW INSTITUTIONAL GEOGRAPHIES OF HIGHER EDUCATION: THE RISE OF TRANSREGIONAL UNIVERSITY ALLIANCES
}

\author{
John Harrison / Darren Smith / Chloe Kinton \\ Department of Geography \\ School of Social, Political and Geographical Sciences \\ Loughborough University \\ Loughborough \\ United Kingdom \\ LE11 3TU \\ $+44(0) 1509228198$ \\ j.harrison4@lboro.ac.uk/d.p.smith@lboro.ac.uk/c.kinton2@lboro.ac.uk
}

This paper has been accepted for publication:

Harrison J, Smith DP and Kinton C (2015) New institutional geographies of higher education:

the rise of transregional university alliances Environment and Planning $A$ 
Abstract This paper opens up debates about the deepening uneven geographies of higher education through a critical analysis of transregional university alliances. Focusing on the formation of research consortia and Doctoral Training Centres we reveal the emergence of over fifty transregional alliances between UK universities. Despite each consortium operating at a variously defined regional scale there has been no explicit attempt to account for their geographical basis. Providing the first-ever analysis of this unfolding phenomenon, we demonstrate how the rise of transregional alliances is indicative of, and a response to, universities operating in an intensely neoliberalised political economy. Bringing together emergent theories of regionalism with emerging worlds of (neoliberal) higher education, our paper reveals how, why and where universities are engaging in more intensively targeted, exclusive approaches to regional development. We argue that higher education is conducive to the weakening of fixed regional territories and propose the metaphor of 'regional constellations' for interpreting transregional geographies. Finally, our analysis suggests that while high-performing research institutions may compete better by forming consortia, transregional alliances lead to a more unequal and divided university sector.

Key words Higher education, transregionalism, relational space, territorial politics, constellatory regionalism, tactical regionalism 


\title{
NEW INSTITUTIONAL GEOGRAPHIES OF HIGHER EDUCATION: THE RISE OF TRANSREGIONAL ALLIANCES
}

\begin{abstract}
"Engagements among universities vary widely, and new forms continue to emerge. There is much to observe and analyse. And, to date, no effort has been made to systematically assess the value universities might receive from entering alliances." (Gunn and Mintrom, 2013: 180)

\section{INTRODUCTION: (RE)PLACING THE 'REGION' IN GEOGRAPHIES OF HIGHER EDUCATION}

This paper advances debates about uneven geographies of higher education through a critical analysis of new and emerging transregional alliances between universities. Our argument is that despite a critical body of literature examining the geographies of higher education at global (Findlay et al., 2012; Jöns and Hoyler, 2013) and local scales (Addie et al., 2015; Goddard and Vallance, 2013; Smith, 2009), investigations of the unfolding regional geographies of higher education are less prominent. This is a particularly significant omission, not least in the UK, where there is a trend for transitioning away from territorially inclusive regional associations to assembling more exclusive, regionally-scaled consortia. Over the past decade, more than fifty research and training consortia have been established, each operating at a variously defined regional scale. Nevertheless, the regional dimension has arguably remained the hitherto forgotten dimension in accounts documenting the new relational geographies of higher education, with no meaningful attempt to account for their geographical basis or potential impact. 
This paper opens up debates on the changing institutional geographies of higher education by providing the first critical analysis of transregional alliances. We contend that these unfolding institutional geographies not only reveal how university-led research and training provision is being reorganised spatially, they provide important pointers as to the intellectual and practical challenges posed by the construction of new regional (as well as other spatial) imaginaries. In undertaking this manoeuvre, we envisage our paper to interface with non-trivial questions of theory. Not least is that our mapping of these new institutional geographies reveals a significant reorientation in the spatial organisation of higher education praxis: away from the relatively uniform pattern of regional space associated with territorial regionalism and ostensibly Keynesian logic for inclusive approaches to regional development, towards increasingly complex configurations of regional space that result from embracing relational regionalism and closer alignment to a neoliberal, free-market insistence on more intensively targeted, exclusive approach to regional development. Moreover, in contrast to other policy spheres, we find higher education to be more conducive to the weakening of fixed regional territories and the emergence of more resolutely relational configurations of networked regions. Our paper also reveals how these institutional geographies are an embodiment of how regions are being intensely reworked - by strengthening and fixing some, weakening or dismantling others, and imagining new ones - to embrace the opportunities presented, and confront the challenges posed, by our increasingly globalised modern world. With the overall configuration of regions becoming ever more complex, fragmented, and, undoubtedly, uneven, we aim to instil some coherence to this debate by proposing the metaphor of 'regional constellations'. In this way, our paper responds directly to Allmendinger et al.'s 
(2014: 2704) contention that "territorial-relational debates have largely been abstract and/or normative and have made few inroads into policy spaces and disciplines".

\section{A 'NEW' REGIONAL GEOGRAPHY OF UK HIGHER EDUCATION?}

A defining moment in the regionalisation of UK higher education came in 1983 when universities in North East England formed the Higher Education Support for Industry in the North (HESIN) to facilitate collaborative industrial programmes around regional innovation. The local success of HESIN, allied to the emergence globally of a new regionalist discourse, provided the catalyst for regional consortia to emerge on a national scale. Regionalisation accelerated in 1997 when the Labour Government embarked on a programme of Devolution and Constitutional Change, creating new institutional spaces in Scotland, Wales, Northern Ireland, London and the eight English regions. An important, yet often overlooked, part of institutionalising territorial regionalism was the establishment of Higher Education Regional Associations (HERA), strategic actors charged with fostering collaboration between member universities and regional partners for the benefit of higher education and the region.

Notwithstanding the formal establishment of HERAs, one region was heretofore laying the foundations for a more exclusive regional geography of higher education. Two

years before a HERA comprising all 12 universities was established in Yorkshire and Humberside, the leading research universities - Leeds, Sheffield, York - formed the White Rose University Consortium to capitalise on their combined research strengths in science and technology. A decade later and this more exclusive brand of university collaboration unfolded across England and Wales with the formation of six panregional research consortia: 
- N8 (or Northern) Research Partnership: established in March 2007 comprising Durham, Lancaster, Leeds, Liverpool, Manchester, Newcastle, Sheffield and York;

- Saint David's Day Group: established in March 2009, Aberystwyth, Bangor, Cardiff, South Wales and Swansea formed a Welsh consortium;

- M6 (or Midlands Six): established in August 2012 as a consortium involving Birmingham, Leicester, Loughborough, Nottingham, Warwick, and, more recently, Aston;

- GW4 (or Great Western Four): established in January 2013 bringing Cardiff together with Bath, Bristol and Exeter ${ }^{1}$ to form a south west consortium;

- SES (or Science and Engineering South): established in May 2013 linking Oxford, Cambridge, Imperial College London, University College London and Southampton across south east England; and

- Eastern ARC (or Eastern Academic Research Consortium): established in September 2013 by East Anglia, Essex and Kent forming a second consortium in the south east.

The result is a new panregional geography of higher education praxis, clearly indicative of why some relationalists argue it necessary to jettison the idea of the region as a fixed territorial entity in favour of relational conceptions of regions (Figure 1; Allen and Cochrane, 2007). But this is only part of the story. For as Pike and Tomaney (2009) usefully surmise, new subnational geographies are marked by a plurality of competing regional (as well as other spatial) imaginaries:

"In the wake of a faltering commitment to regionalization and regionalism, the UK state in England has recently encouraged a proliferation of competing 'spatial

\footnotetext{
${ }^{1}$ Previously the Great Western Research consortium (established 2006).
} 
imaginaries' - cities and/or city-regions, localisms and pan-regionalisms - in order to identify, mobilize and valorize their economic growth potentials" (Pike and Tomaney, 2009: 14).

Higher education is no different: alongside the formation of panregional research and equipment-sharing consortia, the past decade has witnessed a concomitant process of regionalisation through the establishment of consortia level Doctoral Training Centres (DTC) operating at local, city-/sub-regional and panregional scales.

\section{REMAKING REGIONS ALONG MORE EXCLUSIVE LINES}

\subsection{Establishing the foundations for new regional geographies in UK higher education}

Following the establishment of HERA, the regionalisation of higher education was strengthened when Universities UK ${ }^{2}$ and the Higher Education Funding Council for England (HEFCE) commissioned a report entitled The Regional Mission - The Regional Contribution of Higher Education. Reporting at the same time as the UK Government launched its regionally-focused White Paper on enterprise, skills and innovation (Department for Trade and Industry/Department for Education and Skills [DfES], 2001) the HEFCE report reinforced the importance of a 'regional mission' in higher education. The White Paper took the original argument for regional engagement beyond its narrow construction around a singular logic and determinant of success - competitiveness - to introduce more diverse understandings of how higher education contributes to the region's economy and society through widening participation, contributions to local labour markets, and enhanced sustainability. Reinforcing the status quo that regional higher education has to "map onto

\footnotetext{
${ }^{2}$ Universities UK is the representative body for the executive heads (vice-chancellors/principals) of UK university institutions.
} 
the regional development agency boundaries" (Charles and Benneworth, 2001: 24) the main recommendation was to strengthen HERA: "The regional mission should not just be seen as a second best option but as an appropriate element of all higher education institutions' strategies" (ibid.: 25).

Responding to concerns that a weak supply of high-quality scientists and engineers was hampering research and development and innovation performance, the UK Government then commissioned a review into the supply of people with science, technology, engineering and mathematics (STEM) skills. The resulting Roberts Report identified "widespread concern over the level of research and training collaboration between universities and businesses" noting that "although there are excellent examples of innovative and mutually beneficial collaborative research ... there is both the scope and need for the levels of research collaboration to be increased significantly" (Roberts, 2002: 16).

Providing the catalyst for UK universities to adopt the single-institution, interdisciplinary, Graduate School model for training researchers, the Roberts Report focused on internal collaboration. One year later The Future of Higher Education White Paper placed external collaboration front and centre of government policy, with UK Government decreeing "to encourage the formation of consortia, provide extra funding for research in larger, better managed research units, and develop criteria to judge the strength of collaborative work" (DfES, 2003: 23). Support for deeper collaboration between universities was clearly strengthening but crucially the emphasis was shifting from inclusive 'regional' associations to more exclusive regionally-scaled 'consortia'. Indeed, the White Rose Consortium was identified by government as an exemplar for achieving value added from combining the research strengths of selected institutions within regions, rather than 
inclusive formal partnerships that map onto regional boundaries (cf. Charles and Benneworth, 2001). Allied to this, incipient transregional partnerships began emerging, most notably the SETsquared enterprise collaboration between Bath, Bristol, Exeter, Southampton and Surrey in 2003, and the Scottish Universities Physics Alliance in 2005 (Kitagawa, 2009). Furthermore, for the first time there was a clear government policy to promote collaborative practices between UK universities:

"Collaboration should be encouraged, and in a way which reinforces the benefits which it brings when it is done well. But it cannot be imposed top-down. So we do not have a blueprint for particular sorts of collaboration - we want to encourage them to grow organically over time. We therefore intend to reward research that is more concentrated and better-managed, without being directive about the precise shape and formation of those collaborations, and without cutting off funding from others in the sector. The collaborations could take many forms. In each case the central issue will be whether the arrangements add value in terms of improving the quality of research or graduate training. Where institutions already have great individual strength and depth in research across the board, there is no merit in forcing collaboration or cooperation just for the sake of it. Nevertheless, this approach would reward research concentration and synergy, and encourage appropriate collaboration between institutions" (DfES, 2003: 29).

The implications arising from this policy framework should not be understated. Not least is evidence of a move from promoting collaborative activity within a predetermined regional template - defined by the state and where participation is predetermined by an institutions geographic location - towards allowing universities to actively (re)invent regions based on their own collaborative practices. Despite the promise of an all-inclusive approach to funding, in practice universities were encouraged to discipline and rank themselves. Highperforming research institutions were rewarded for organising themselves into exclusive groupings, and by virtue of this responsibility for cutting funding to other institutions had 
passed from central government to universities. Rewarding research concentration signalled greater alignment with neoliberal free market imperatives for more intensively targeted, exclusive regional development. While for the first time an indication that collaboration for research and training - united in the Roberts Report - could be organised separately was provided. Each important in their own way, together they opened the way for the plurality of regional (and other spatial) imaginaries, operating at different spatial scales and according to different spatial logics, to significantly alter the landscape of UK higher education.

These policy shifts prompted HEFCE to undertake a review of HERA. HEFCE discovered that those who thought HERA were unimportant or added little value identified a threefold problem with the way HERA were spatially configured: (1) "institutions sit[ting] close to the geographical edge of their regions, see their natural collaborative partners in neighbouring regions"; (2) institutions who see their role principally as national and international players "believe that $\mathrm{HE}$ is and will continue to be more competitive than collaborative, and that the future is one in which strategic alliances will prevail"; and (3) "very different geographical distributions of HEls around regions ... can have a significant effect on their willingness to collaborate within the HERA framework" (Brickwood and Brown, 2005: 5-6). Although a minority view, these points take on added significance as the spatial reorganisation of UK higher education gathered pace in the late-2000s. How the story develops is distinguished from the different viewpoints of collaboration for research and collaboration for training.

The remainder of the paper draws on a combination of desk-top research, spatial analyses and mapping, and interviews. Desk-top research involved analysing policy and strategy documents, press releases, and publicly available data on university research 
income and performance. Maps were produced using ArcGIS and Adobe Creative Suite to provide the important first visualisation of these transregional alliances. Institutions were plotted by postcode (using MapPoint) before being assigned symbols based on their mission group and connecting lines added. For clarity overlapping symbols were separated. In 201415, twenty interviews were conducted with actors involved in transregional alliances, exHERA officials, and representatives of national sector organisations. All interviews were fully transcribed, systematically coded, and analysed. Anonymised quotes highlight key points of concern expressed.

\subsection{Collaboration for research: a new archipelagic regionalism of higher education} praxis

Figure 1 reveals a striking image of research consortia producing a new archipelagic regional geography of higher education praxis, but what it fails to uncover are the different ways universities are mobilising the region. What clearly unites universities in research consortia is their desire to regionalise higher education along different lines. The starting point for most consortia $\mathrm{HEI}$ was a desire to remake extant regions along more exclusive lines by identifying a set of elite universities located in the region. We see this clearly with the reimagining of Yorkshire \& Humberside as the trilateral White Rose Consortium, Northern England as N8, the Midlands as M6, and the South West as GW4. Territorial regionalism was not as deeply embedded in the south and east of England meaning new transregional spaces were constructed for SES and Eastern ARC. Each new region has elements of spatial continuity but this new expression of relational regionalism has seen institutional actors interested in self-defining a hierarchy of research excellence elevate their status. Those institutional actors are the large research-intensive - Russell Group - universities who have 
the highest national and international aspirations and gain most from assembling more exclusive groupings. This is evident in that 18 of 21 (86\%) Russell Group universities in England and Wales are part of a research consortium, whereas the 1994 Group, representing smaller research-intensive universities, had 14 members of which only 6 (43\%) are consortia members ${ }^{3}$, and University Alliance and Million+, which represent 38 newer universities, have no presence in consortia. The implications of this are not going unnoticed:

"Why do you create a premier league? Why do you create a Russell Group? It's so that you can pull up the gates behind you" (interview, 1994 Group, non-member institution).

"Clearly the biggest threat here is the dominance of a cluster like the Russell Group" (interview, 1994 Group, member institution).

That said, not all consortia are equal. Superficially similar, research consortia are differentiated by resource, political weight, research power and strategic intent. In 2015/16 SES institutions receive $34 \%$ ( $f 530 \mathrm{~m}$ ) of the $£ 1.56$ billion research fund awarded by HEFCE, f246m more than N8 (18\%), and 2.7, 3.2 and 13 times more than M6 (10\%), GW4 (8\%), and Eastern ARC (2\%), respectively (HEFCE, 2015). This is reflected in their strategic intent. For SES their strategic intent is offensive: to "represent the most powerful cluster of research intensive universities in the world" (University of Southampton, 2013, np). N8 and GW4 are better resourced ${ }^{4}$ and "further downstream than SES" with working collaboratively (interview, SES university), but their strategic intent is "defensive, a way to compete against the Golden Triangle of Oxford, Cambridge and London" (interview, N8 university). M6 remained an equipment sharing consortium with some strong bilateral relationships,

\footnotetext{
${ }^{3}$ The 1994 Group was dissolved in November 2013.

${ }^{4}$ In terms of institutional support, staff and organisational structures.
} 
however, the announcement in March 2015 that the UK Government is to invest $f 60$ million in an M6 Energy Research Accelerator hub and the appointment in July 2015 of their first Director suggests this too may start to morph into a more substantive alliance. Eastern ARC remains the weakest consortia, emerging in response to "the East of England being left off the map" (interview, Eastern ARC).

There are important differences within consortia too. Institutional ties between member institutions are not all equal, with strong bilateral and trilateral arrangements dominating some consortia. Allied to this is the relative weight and status of member institutions:

"Like it or not with the SES consortia, it is some of the biggest research intensive universities in the world joining in a loose consortium. Oxford, Cambridge, Imperial, $\mathrm{UCL}$ are pretty massive institutions in their own right. That's not the same with N8 where you've got an imbalance of institutions. You've got some really dominant ones - Manchester, Leeds, Sheffield - and some less dominant ones in Lancaster and York" (interview, SES university).

Further highlighting the imbalances within research consortia, across the Golden Triangle members of SES Oxford ( $f 139.1 \mathrm{~m})$ receives $48 \%$ more research funding from HEFEC than Imperial $(£ 94.1 \mathrm{~m})$, whereas in N8 Manchester $(\mathrm{f} 68.8 \mathrm{~m})$ receives $263 \%$ more research funding than Lancaster (£18.9m) (HEFCE, 2015).

A second explanation is that higher education is not the only policy sphere to favour more exclusive regional groupings. In England, the previous Labour Government's faltering commitment to territorialised regionalism has seen the UK state actively endorse cityregionalism as a more targeted approach to regional economic development. Launched in 2004, The Northern Way was synonymous with this new approach. A defensive policy response to the 2003 Sustainable Communities Plan prioritising further growth in parts of 
south east England, the Northern Way reimagined northern England as a panregional grouping of eight city-regions spanning the North East, North West and Yorkshire and Humberside regions. Reconfiguring the UK space economy along more exclusive lines was fully evident when three more identikit initiatives appeared in England - The Midlands Way (spanning East and West Midlands) in 2004/5, The Way Ahead (South West) in 2005, and Regional Cities East (East of England) in 2006 - and Wales became reimagined along similar lines (Heley, 2013).

The significance of these relationally-inspired transregional geographies cannot be overestimated; for in part they became active determinants in shaping the geographical basis of research consortia. In England and Wales, reassembling regions along more exclusive lines for economic development and higher education produced analogous spatial configurations: hardly surprising when you consider the N8 Research Partnership was launched by the Northern Way and received $f 6$ million to establish its virtual Research Centres in science, engineering and technology. Moreover the remaking of regions along more exclusive lines unfolded in almost identical fashion, with momentum gaining as the invention of one transregional space triggered responsive developments throughout the UK. In the case of economic development, this process was clearly expressed in the Midlands where policy elites recognised that having "missed out in the recent spate of plan-making activity" they had "been left to fend for themselves in a no-man's land of regional policy", and urgently needed "to rectify this" by developing their own arrangements - The Midlands Way (Town and Country Planning Association, 2005: 2). In higher education, the trigger came with the UK Government's Innovation and Research Strategy for Growth report, which equated success in the global innovation economy to the growing importance of research consortia: 
"We believe that funding mechanisms for research and innovation should recognise the value of collaborations between organisations. Consortia can tackle large-scale and ground-breaking new research beyond the capabilities of a single institution [...]. To make clear that such approaches are welcomed, Research Councils UK, working with UK HE funding bodies, and in discussion with individual universities and consortia, will establish a principles-based framework for treatment and submission of multi-institutional funding bids" (BIS, 2011: 54).

With its former director, Sarah Jackson, seconded to BIS to help formulate government policy on consortia, this report presented N8 as a model for others to emulate. Akin to the roll out of city-regionalism, universities beyond the N8 mobilised to form panregional research consortia in the Midlands (M5), south west (GW4), and south east (SES and Eastern ARC). By September 2013 new panregional geographies of research collaboration had been consecrated in the UK, co-determined in an intensely neoliberalised environment by research-intensive universities - particularly those located outside the Golden Triangle - beginning to organise themselves in this way to better compete nationally and internationally, and by HEFCE and the research councils seeing the new institutional arrangements as a way of demonstrating efficiencies to their sponsor department (BIS) at a time when HM Treasury are imposing stringent controls to drive down departmental expenditure limits.

The most striking feature of this new geography of higher education is the formation of an archipelago of panregional consortia (Figure 1). Consortia are not coterminous, nor are they overlapping. Indeed, the spatial configuration of higher education research and equipment sharing consortia is almost identical to the relationally-inspired city-regional

\footnotetext{
${ }^{5}$ Acting on this HEFCE published Collaborations, Alliances and Mergers in Higher Education - Consultation on Lessons Learned and Guidance for Institutions in March 2012.
} 
geographies which emerged in the mid-2000s (Harrison, 2007). Nonetheless, there are some not insignificant differences: (1) the south east went from the vanguard of non-territorial regional spaces for spatial economic governance to last responder when forming transregional research and equipment-sharing consortia; (2) the White Rose Consortium continues to be recognised as both an independent regional consortium and component of the panregional N8 consortium; (3) Cardiff is now included in what was originally a South West consortium, making GW4 the only cross-national consortium; (4) although the vast majority of cities are present in both discursive framings there is one notable exception Hull, included in the Northern Way is not part of N8, while Lancaster, included in N8, was never formally part of the Northern Way; and (5) the geography of university research consortia is less spatially inclusive (cf. Harrison, 2010; Heley, 2013).

\subsection{Collaboration for training: the galaxy of graduate training partnerships}

The 2002 Roberts Report provided the catalyst for regionalising training programmes in UK higher education with the single-institution, interdisciplinary, Graduate School model clearly evident when the Engineering and Physical Sciences Research Council (EPSRC) became the first UK Research Council to establish DTCs in 2009. Funded by the Science Budget of BIS, focusing on STEM research subjects, and evolving from predecessor EngD centres (established 1992) and the Life Science Initiative centres (established 2002), it is not surprising the EPSRC were the trailblazers in establishing the new model DTCs. From an initial 45 centres, the EPSRC accredited 80 single institution centres with approximately f390m of funding (Figure 2).

In 2010, the Economic and Social Research Council (ESRC) established its national network of 21 DTCs. The most noticeable development was the mix of 12 single institutions 
and 9 consortia (average size, 3.9 institutions) (Figure 3). Similarly, the Biotechnology and Biological Sciences Research Council (BBSRC) announced 14 DTCs in 2012, comprising 4 single institutions and 10 consortia (average size, 3.2 institutions) (Figure 4). Presently, the Arts and Humanities Research Council (AHRC) operates with 7 consortia DTCs (average size, 5 institutions) and 11 Doctoral Training Partnerships (DTP), including 2 single institutions and 9 consortia (average size, 5.5 institutions) (Figures 5a \& 5b). Finally, the Natural Environment Research Council (NERC) announced its national network of 15 DTCs in 2013, comprising 4 single institutions and 11 consortia (average size, 3.5 institutions) (Figure 6) ${ }^{6}$.

From this we can make a number of observations: (1) a declining role for single institutions and trend towards multi-institution DTCs; (2) training consortia are not spatially coterminous but unlike research consortia there is extensive spatial overlapping; (3) DTC consortia are becoming less localised; and (4) the overall geography became more obviously multi-layered, less coherent, and increasingly complex as each research council produced its own national network of DTCs. What the maps also reveal is that despite the same fundamental principles of 'selectivity' and 'concentration' being applied by each research council, how each research council engages with their key universities reflects their individual priorities and results in a distinct regional geography. For example, the EPSRC's more purist, 'fund the best' approach is very evident in the unevenness of DTC awards made to individual institutions (Figure 2). This unevenness is less visible in the other maps, but is nevertheless present. The AHRC goal of 'capacity building' resulted in a two-tier system comprising 'centres' and 'partnerships' (Figures 4 \& 5), and although the maps reveal the

\footnotetext{
${ }^{6}$ The Medical Research Council and Science \& Technology Facilities Council are omitted because they award studentship quotas to single institutions and do not add significantly to our analysis.
} 
impact spatially of their more inclusive approach, the unevenness is masked. Nevertheless, our interviews revealed important differences between the research councils:

"If you look at AHRC studentships, the White Rose Consortium received $90 \%$ of what they asked for - something like 270 studentships - and we received $66 \%$ of what we asked for, meaning 26 studentships. It's not a level playing field" (interview, AHRC consortium manager).

"NERC bottled it and just gave each consortium nationally 15 studentships" (interview, research consortia executive).

Further imbalances exist within consortia because while institutions collaborate in a DTC to secure research council studentships, many operate openly competitive systems between institutions to then allocate those studentships.

Perhaps most significant is how these maps show higher education becoming more conducive to the weakening of fixed regional territories, and the emergence of more resolutely relational configurations of networked 'regional' spaces. This is in contrast to accounts which have revealed the persistence of state-territoriality in constraining attempts to de-territorialise subnational planning and governance arrangements (MacLeod and Jones, 2007; Harrison, 2013). To investigate this further, the remainder of this paper moves from questions of definition, identification and delimitation to questions of agency (who or what is behind the new regionalisation of higher education), process (the actual mechanisms by which the new regionalisation of higher education is occurring), and specific interests (why has the new regionalisation of higher education taken the form it has).

\section{TACTICAL REGIONALISM}


In 1997 the Department for Education and Employment surveyed UK universities, finding that $61 \%$ gave a rating of high importance when asked if regional economic development was important to their mission. In their own survey, Universities UK found $78 \%$ of universities regarded regional economic development a higher priority than in the mid1990s, with the remaining $22 \%$ seeing a similar level of prioritisation (Charles and Benneworth, 2001). This is no coincidence: the 1990s saw a discourse of regional competitiveness become hegemonic within public policy circles and regions extolled as competitive territories par excellence (Bristow, 2005). Yet, for all that competitiveness thinking did to energise the new regionalism debate and legitimate intervention at the regional level, two disputed points are pivotal for understanding the new regionalisation of UK higher education.

The first relates to the exposure of regions to increased interspatial competition. The rolling-back of spatial Keynesianism intuitively led to concerns that regions were being thrust headlong into a competitiveness game where their ability to prosper and grow relies on them out-competing other regions. Certainly competitiveness thinking has inspired a generation of regional strategies riddled with narcissism and the mantra of regions outperforming their rivals. Nonetheless, while regions do compete vigorously to attract skilled labour and mobile capital, as supply chains have penetrated regional boundaries with increasing regularity, and the need to create external markets for goods and services became more prevalent, regions have become more dependent on each other for their success. In other words, globalization is redefining competition by making collaboration the new competition ${ }^{7}$.

\footnotetext{
7 'Collaboration is the new competition' has become a popular mantra among management gurus, company directors, and strategists for what is seen as critical to achieving success in today's globalizing world.
} 
A second dispute is the extent to which formal structures of state territorial governance stifle competitiveness. Intellectually, the argument which has developed with globalization is that fixed territorial boundaries act as a barrier to competitiveness because they "are always likely to put the brakes on exchanges and cooperation" (Sohn et al., 2009: 937). Illustrative of this is the continued measuring of competitiveness through league tables and performance metrics, instruments which incentivise regions (and universities) to compete more than they collaborate. Practically, one important consequence of global competitiveness thinking are demands for more 'appropriate', taken to mean more flexible, networked, and smart arrangements.

From this we can start to make a number of important assertions regarding the new regionalisation of higher education. First, as Colin Riordan (Vice Chancellor Cardiff University) explains, the emergence of university consortia is a direct response to an increasingly competitive higher education sector:

"We want to enhance Cardiff's world-leading research and reputation by creating a critical mass of research excellence with other UK universities. In a competitive higher education sector, we need to find new ways for Wales to compete for research income. Working in collaboration with fellow Russell Group and researchintensive universities will help us to succeed ... Critical mass is the key to success and the combined research excellence of Bath, Bristol, and Exeter will give Cardiff - and Wales - a new and competitive edge ... not only in the UK, but internationally" (quoted in GW4, 2013).

Embedded within this quote are important pointers for understanding what motivates transregional collaboration. The ranking of universities in national league tables is relatively stable so actors increasingly explore new ways to compete better for research (and other) income. Collaboration is important because it results in critical mass. In the same way that larger economic units are seen to outperform smaller economic units universities are 
seeking to capitalise on the same competitive advantages as business and industry to succeed in a hardened national and international competitive climate for higher education (Kitagawa, 2009, 2010) ${ }^{8}$. Recent work by Gunn and Mintrom (2013) shows universities belonging to an international alliance performing 'significantly better' in university rankings, while our research reveals that relative to their position when consortia were established institutions in research consortia perform significantly better (gaining on average $3 \frac{1}{2}$ places) than non-consortia institutions (losing on average 4 places) in university rankings (Harrison et al., 2015).

The second assertion is that the spatial configuration of UK higher education is showing signs of 'breaking free' from localities and regions. Consistent with research conceptualising spatial economic governance (MacLeod and Jones, 2007; Harrison, 2013), the formation of research consortia and the first wave of training consortia were clearly shaped by the institutional legacy of the Labour Government's commitment to territorial regionalism in England ${ }^{9}$ (Figures 1-3). Unequivocal in their contention that "regional and other strategies stifled natural and healthy competition between places and inhibit growth as a consequence" (BIS, 2010: 7), the Conservative-led Coalition Government's (2010-15) move to abolish regional strategies and institutions paved the way for the increasingly deterritorialised maps of doctoral training provision. Unlike many other policy areas higher education appears to be where the legacy of regions and other territorial strategies is now proving less of a barrier to the creation of new, more networked, flexible, and loosely-

\footnotetext{
${ }^{8}$ Universities increasingly compete globally to attract and retain top talent, attract high-fee paying international students, and position themselves within increasingly influential global university rankings.

${ }^{9}$ For example, ESRC DTCs in the North East, North West, South West and Yorkshire \& Humberside remain regionally-embedded but remade along more exclusive lines.
} 
bound institutional arrangements (Figures 4-6). That stated, territory and territorial politics continue to play an important role. For the question facing many HEls is not whether to participate in variously defined 'regional' research and training consortia, but deciding who to collaborate with, what to collaborate on, and how to collaborate to compete better.

\section{BUILDING NEW ALLIANCES, FORMING NEW RIVALRIES: SOCIAL ACTORS AND THE TERRITORIAL POLITICS UNDERLYING}

Deciding which institutions to include in consortia is important, but equally important is which institutions not to include. For the creation of new spatial imaginaries brings with it new geographies of inclusion/exclusion while new alliances inevitably mean (re)new(ing) rivalries. In this final section we examine five considerations for universities when collaborating in consortia.

The first consideration is prestige. Research-intensive universities dominate research consortia and this reaffirmation of elite mission group universities is evident in networks of DTCs. Across the major research councils the majority of large research-intensive Russell Group universities are included: AHRC (83\%), BBSRC (85\%), EPSRC (86\%), ESRC (73\%) and NERC (87\%). A similar story exists for the smaller research-intensive universities, although there is a significantly smaller presence in STEM training networks: AHRC (73\%), BBSRC (60\%), EPSRC (40\%), ESRC (80\%) and NERC (73\%). What this adds up to is a consistent picture across four of the five research councils. Only $15 \%$ of institutions for BBSRC, $14 \%$ for EPSRC, $11 \%$ for ESRC and $14 \%$ for NERC are not self-identified as research-intensive universities. Only the 'capacity building' aim of the AHRC sees $45 \%$ and $70 \%$ of institutions included in its national networks being unaffiliated to either the Russell Group or 1994 Group. What we take from this is that not only are the larger research-intensive universities 
likely to gain most from these transregional institutional geographies of higher education, they are the only ones likely to gain significantly. This is not to say that other universities will be excluded completely, rather it is to say that a metaphorical drawbridge is being pulled up behind the larger research-intensive universities, as an ever-decreasing number of universities are able to compete at the top table in UK higher education. Moreover, this is becoming a significant issue for an increasing number of larger universities:

"One of the more general trends is those universities in the middle are the ones that are being squeezed because they're not necessarily big enough or good enough to ensure that they get DTCs. They have to join with others to do that and that forces them to make decisions about where they see themselves in the pecking order" (interview, ESRC DTC coordinator).

This implies institutions have a degree of control over their destiny, but our research reveals they are quite often powerless in these discussions, particularly with the desire of the elite universities to remake regional consortia along more exclusive lines gathering momentum:

\footnotetext{
"We discussed collaborating with them in a DTC bid and we were potentially quite keen to do this at the start. But from our end we have a quality threshold. We are Russell Group universities; in the top ten, top twenty nationally. We're research intensive and our senior leaders don't want to do anything that would be seen to jeopardise that. Not that I'm saying the evidence of their research is not world class, but they're not an institution necessarily in the same position as us, so that put an end to it" (interview, ESRC DTC coordinator).
}

A second consideration is geography and spatial proximity. For research consortia, spatial proximity is vital to enable equipment sharing, however, this appears less important for training partnerships. One indication of this is that while all research consortia are named after their geographical location, only $58 \%$ of DTC consortia attach themselves to a particular place or region. What is most striking about the sequence of maps is how spatial 
proximity appears to become a less significant factor as each research council established their DTC network:

"Regionally, the way things have shaped up is a natural configuration about how institutions work together. When you're asked to do something collaboratively, you immediately, quite naturally, turn to the institution that's 15 miles up the road. With the ESRC being in the first wave that was compounded. We've done subsequent DTCs in other Research Councils where the geographical constraints or issues are starting to break down as people understand what it's about" (interview, ESRC DTC coordinator).

That stated, we also see a number of regions where actors are actively engaged in an exercise to 'fix' their region (Allen and Cochrane, 2007). Leading the way is the White Rose Consortium which has established DTCs on the same trilateral agreement as their research consortia. Likewise, an agreement now exists between members of GW4 to ensure they collaborate in all future DTC competitions, solely as GW4 or as GW4+ where external partners are brought into a lager consortium to complement the core strengths of GW4, and analogous discussions are evident in the Midlands.

This leads straight on to a third consideration which is a desire to colonise expertise in specific research areas by creating a 'super-strength' alliance. The aim for universities entering into this type of alliance is to elevate them to a position where they become the undisputed centres of excellence nationally while gaining the critical mass necessary to better compete globally. This was certainly the rationale for SES. University leaders recognised that to better compete in a hardened international competitive climate for higher education meant "total dominance" in science and engineering was a "no-brainer" (David Price, Vice-Provost (Research) University College London, quoted in Jump, 2013). Where expertise is the main determining factor for collaboration, geography can sometimes 
follow but the attachment to place (or region) is typically weak. We see this in the SES example, where geographical attachment to place (the South) and colonising expertise (science and engineering) are coterminous:

"If we just drew a circle, there are clearly other universities in the SES area. But in terms of the volume of research that's occurring it's on a much smaller scale, less research intensive, and not dealing with same issues. The consortium was set up because these five universities have the biggest share of EPSRC funding. That was a rationale and they just happened to be geographically co-located, which made more sense for us to start sharing things" (interview, SES university).

However, in many other cases - e.g. the AHRC Heritage Consortium - there is no significant geographical attachment to place suggesting that when 'expertise' and 'geography' are complementary it is more happenstance than any deep-rooted sense of regionalism. What the SES example also demonstrates is that when expertise becomes a major determining factor in collaboration, even having the status of being a large research-intensive university located within close proximity can be insufficient. In London and the south east this is a particular issue for Kings College London, which despite receiving $f 20 m$ (44\%) more research funding than the lowest ranked SES member (Southampton) (HEFCE, 2015) is excluded due to a lack of expertise in one particular research area:

"for Kings the issue is this is 'science and engineering' and they don't really have an engineering department. Most of our collaborations with Kings are in the medical sciences and the focus of SES is not medical" (interview, SES university).

Nevertheless, a major challenge when pooling expertise in areas of strength is those institutions are traditionally direct rivals when competing to attract top academic talent and win research contracts, so a fourth consideration is that some institutions wish to find partners who have research strengths in their area(s) of weakness to create a 'strong- 
across-the-board' alliance. Not only does this have the major advantage of alignment with institutions that are less directly threatening to the day-to-day business of running their university, it enables institutions to engage in collaborative projects and programmes that they were previously unable to deliver independently.

The final consideration relates to institutional ties, particularly personal and professional ties between university leaders. According to Trevor McMillan, then Chair of the N8 Management Board, the "real value" of university consortia "comes when there is well-embedded trust at senior levels - and this does not come quickly or easily" (quoted in Jump, 2013). Akin to partnership working in other contexts personal and professional ties are critical factors in determining which collaborations are established, maintained and developed, and on what terms. Personal and professional ties are the glue that holds university consortia together, but they take different forms and play a different role in the different types of collaboration mentioned above. For many universities, working in collaboration is not about creating new partnerships; it is about strengthening existing partnership arrangements - a case of "providing new names and new infrastructures for what are often historic relationships between institutions and their leaders" (interview, DTC coordinator).

Moving the discussion forward from the question of process to the question of outcomes, being included within this new regional landscape of higher education could have far reaching consequences because what we see with the trans-regionalisation of higher education is a modern day example of Doreen Massey's classic thesis that the character of a region is the result of the accumulated history of that region. In the economistic terms which Massey's (1984) arguments were developed, (regional) space is constructed from the 
specific combination of past 'layers' of investment which, in turn, influence future rounds of investment. As one interviewee put it:

"We knew if we got the DTC we could use it as a landing platform for other ESRC investment. Having been interviewed by ESRC, that's what they're interested in effective management and governance structures and the ability to spend public money and match it. They're not that fussed about the academic punch. If you look at the last two years of ESRC funding, bids are getting awarded not because they are academically the best but because you've got pre-existing investment from the ESRC and elsewhere. So you've got to be in this game [DTCS] to play other funding games. The question then becomes, when the cut off line gets higher and higher because of less money does that lead to a concentration of who can play the game? Well yes, because you can't play it unless you've got the money anyway" (interview, DTC coordinator).

As the longest established formal research consortia, the White Rose Consortium is almost fully institutionalised, successfully establishing White Rose DTCs for three of the five research councils and its universities offering doctoral training for the five research councils. Other research consortia are at different stages in this process. In the latest rounds of DTC awards GW4 and Eastern ARC have both started to actively institutionalise their more exclusive regional arrangements. In contrast, SES continues to operate with very few institutional ties because "enough institutions remain strong enough in their own right not to have to collaborate" (interview, 1994 Group university), but there is a recognition that this may need to change:

"We ought to be encouraging much closer working between Imperial, UCL and the Golden Triangle because individually they may be excellent but they have not got scale like some of our international competitors" (interview, DTC director).

Conversely within-region ties between universities are being broken and previous regional layers eroded to make way for these more exclusive regional groupings. The University of 
Liverpool's decision to stop paying its subscription was all it took to make the North West Universities Association untenable, a demonstration that although the old HERA approach was regional in the sense that it placed universities within an existing regional template this was not a particularly deep-rooted regionalism. Moreover, the decision to leave the NWUA can be connected to the formative stages of establishing more selective consortia arrangements, and manoeuvres to ensure Liverpool was well placed to take advantage of the new institutional landscape:

"Interestingly the North West's ESRC DTC is run by Liverpool. Now you think to yourself, how did that happen? It should be Manchester because they're the biggest player. But the loudest Vice Chancellor is Howard Newby. Newby is ex-HEFCE, exESRC, he pulled Liverpool out of the NWUA, and he is very, very vocal in promoting the N8, so work that out?" (interview, DTC coordinator).

Albeit arguably very weak within-region ties were eroded by the demise of the old HERA approach in many regions, there is increased recognition that the trans-regionalisation of higher education has brought with it much deeper differentiation of the HE sector than was originally intended.

This is best exemplified by the ESRC who initially planned to accredit two types of institution: larger DTCs which had an annual allocation of studentships and smaller Doctoral Training Units (DTUs) eligible to hold studentships but without an annual allocation. Many of the original ESRC bids were more inclusive, self-identifying elite national-level universities for DTC status along with DTUs to recognise those pockets of research excellence which exist in some of the smaller, less research intensive universities located in the region. Yet, because the commissioning process coincided with a $12 \%$ real terms decrease in the ESRC budget following the UK Government's 2010 spending review - the consequence of which 
was a drop from 750 to 600 studentships annually leading the ESRC to raise the assessment threshold - none of the planned DTUs were commissioned. Becoming even more concentrated than originally envisaged or intended there are concerns that the ESRC structure is "very strongly two-tier", where the "relatively impermeable boundaries" created between DTC and non-DTC institutions mean barriers to entry are "very formidable and discouraging" (Bartholomew Report, 2015: 31), and the consequences for institutions falling 'off the map' appear stark:

"If you've not got a doctoral training centre you're in real trouble. It's not the money so much - it's the kitemark. It's like musical chairs. The chair gets pulled away and if you've got nowhere to sit what happens?" (Steve Smith, Vice Chancellor, Exeter University, and President, Universities UK 2009-11, quoted in Fazackerley, 2012).

As the highest ranked university not included in a research consortia or offering RCUK doctoral training provision the most notable absentee is the University of Hull. In part, this is a consequence of the Hull becoming isolated from the other research-intensive universities in northern England when, despite the city being integral to the Northern Way, the university was not included in the N8 research partnership. To put this in context, apart from Liverpool which offers doctoral training provision for four of the five research councils the remaining N8 universities provide doctoral training for all five research councils. It is therefore interesting to observe that since the formation of N8, consortia institutions have risen by an average of 5.25 places in the Complete University Guide while Hull has dropped 27 places (Harrison et al., 2015).

\section{CONCLUSION - TOWARDS CONTELLATORY REGIONALISM?}


This paper has examined the hitherto overlooked transregional geographies of higher education. Focusing on the establishment of over fifty multi-institution research and training consortia and doctoral training programmes in the UK, our starting point was the need to analyse the geographical basis of these new geographies of higher education praxis. In an empirical sense we see our paper contributing to wider debates about uneven and relational geographies of higher education, which have been overlooked by researchers more focused on global and local perspectives.

We also see our analysis contributing to wider conceptual interests, most notably in relation to the construction of new regional spaces and imaginaries. Our paper reveals three distinct forms of regional arrangement. The first is a territorial regionalism seen with the old HERA approach. Here a regional template and structure is imposed from above, universities are obliged to operate within it, and the geographical basis is a relatively uniform pattern derived from a singular, ostensibly Keynesian logic for more inclusive approaches to regional development. The second is an archipelagic regionalism whereby inclusive, territorial identities are dismantled in favour of forging new regional identities along more exclusive, relational lines. We see this clearly with the formation of research and equipment-sharing consortia where regions have been remade along more exclusive lines by universities selfselecting a set of elite institutions located within the region(s). Aligning universities more closely with the neoliberal free-market insistence on more intensively targeted, exclusive approaches to regional development the result is a smaller number of larger, increasingly self-selected groupings which are archipelagic in their appearance. Finally, there is de facto regionalism. This can be seen with the formation of DTCS, a policy not favouring regional arrangements per se but where research council requirements for universities to collaborate to access their funding and receive their kitemark serves to produce a de facto 
regionalism. Unlike territorial and archipelagic regionalisms, which are underpinned by singular logics (Keynesianism/neoliberalism) and produce relatively uniform spatial scales (regional/pan-regional), de facto regionalism operates at different spatial scales (local, city/sub-regional, trans-regional), and according to different imperatives (e.g. offensive, defensive) and logics (e.g. expertise driven, proximity, institutional ties). The resulting regional geographies are very obviously complex, tangled, and, indeed, messy. All of which raises important questions around how best to conceptualise these new spatial imaginaries and extend our relational vocabulary. Indeed, to better account for these new, more exclusive and relational regional imaginaries we propose the concept of constellatory regionalism.

Derived from the Latin word constellatio (com- together + stella- star), the term constellation is used in astrology to refer to a series of irregularly defined assemblages convenient in breaking up the night sky. There is also no scientific reason why there are currently 88 constellations while various cultures have chosen different groups of stars to form different constellations throughout history. And in their naming, individual stars within constellations are differentiated in order of brightness. Relating this to the geographies of higher education, by constellatory regionalism we refer to the ways in which the best performing ('star') universities are coming together to form consortia, that is, irregularly defined groupings that are felt to be related and to which definite names are given. As constellations conveniently break up the night sky consortia provide research councils with a convenient way of organising their funding of higher education research and training. Added to this, it is generally only the brightest stars/best performing universities which are included in constellations/consortia, each research council has identified different groupings 
of universities to form different consortia, and within consortia some universities are more prominent than others.

By constellatory regionalism we also refer to the way in which the lines connecting stars in the night sky and universities in consortia are only useful in defining space. Despite a new expression of (relational) regionalism being clearly evident at no point does this imply a particularly deep-rooted regionalism. As one interviewee remarked:

"If universities are collaborating then, by definition, that's a regional collaboration, but it doesn't define a new regional geography unless lots of other things are happening around that" (interview, ex-HERA official).

What our research reveals is research and equipment-sharing consortia are striving towards stronger institutionalised forms and deeper-rooted regionalism through a process of layering up DTCs, and research funding along their more exclusive lines. This is in stark contrast to de facto regional arrangements which are likely to remain fragile institutional forms. Meanwhile, recent state sponsored geographies may also provide scope for harder institutional forms to develop. In contrast to work connecting individual universities to city or city-region practices (Addie et al. 2015; Goddard and Valance, 2013), our analysis points towards connecting consortia of universities to a broader urban economic geography. For our part we have shown the reassembly of regions along more exclusive lines to take on a remarkably similar appearance in both higher education and economic governance (e.g. N8 and the Northern Way). With the UK Government reigniting proposals for an urban agglomeration economics inspired Northern Powerhouse along similar lines to N8 (and analogous proposals for a Midlands Powerhouse and Severn Powerhouse complementary to M6 and GW4 respectively) we see one example where the new transregional geographies of higher education have potentially wider political and economic significance. 
This brings us to our final point which is the wider political significance of university consortia. Research concentration favours the most ambitious universities with national or global ambitions for elite status. This ensures the interests of the powerful Golden Triangle institutions in London and the south east are protected but the consequence is highperforming institutions in northern and western Britain are having to engage in a tactical regionalism, detaching themselves from universities more focused on what they do regionally or locally to form alliances with institutions who share aspirations to compete nationally and globally. Defending their interests against the external threats of concentration of investment in Golden Triangle institutions ${ }^{10}$ and the UK Government's push to further marketise the higher education sector, collective resistance through collaborative partnerships is the defence which many research-intensive universities are adopting to stay competitive in an increasingly hostile, progressively neoliberalised politicaleconomic environment within which universities operate:

"For us to be able to compete in those domains now my university just cannot ever turn around and say, other than in a very small niche area, we can compete with [the Golden Triangle]. The only way we can do it is by having critical mass through partnerships" (interview, Russell Group university).

\footnotetext{
${ }^{10}$ This external threat of investment being concentrated in Golden Triangle institutions is being fuelled by developments such as the Francis Crick Institute - a f650m partnership (launched in 2007 and due to officially open in 2016) between the Medical Research Council, Cancer Research UK, the Wellcome Trust, UCL, Imperial College London and King's College London to pioneer biomedical research - which is based on a very different model of collaboration, where critical mass is concentrated in place as opposed to secured through partnerships across space.
} 
A process of "cut-throat collaboration" (interview, 1994 Group university) results as research-intensive universities respond to external threats by forming transregional consortia which, while better insulating their institutions from this hostile environment, make the world far more hostile for, and threatening to, institutions outside a consortium or weaker members within a consortium. Serving to further exacerbate the already uneven geographies - both inter- and intra-regional - of higher education in the UK these new institutional geographies have the potential to mask a far bigger consequence for the economic geographies of higher education:

"Consortia are manna from heaven for BIS. When they hear this they just think this is wonderful. All the people in the Government think this is great because universities are going to reduce their capital spend on equipment. It is Government policy basically, part of austerity. The problem is universities are now a hostage to fortune. By forming consortia and saying, look we can save a few quid here and there it sends the wrong message to BIS and Government. It sends a message that says, yeah, give us less and less and we can still cope. That's not the right message. We need more, not less, investment" (interview, SES university).

This suggests that although research-intensive universities see the formation of transregional consortia as the only option to insulating themselves from the threats posed by operating in an intensely neoliberalised political-economic environment, it is not necessarily for the overall good of the higher education sector; rather they are codetermining a future higher education system where their standing still financially comes at the expense of those less research intensive universities which nevertheless contribute in other important ways to the functioning of the sector as a whole. 


\section{ACKNOWLEDGEMENTS}

We are indebted to Jamie Peck and three reviewers for their insightful comments which proved extremely helpful in refining and furthering various lines of argument. We are also grateful to Mark Szegner for his cartographic assistance. 


\section{REFERENCES}

Addie J-P, Keil R, Olds K, 2015, “Beyond town and gown: universities, territoriality and the mobilization of new urban structures in Canada" Territory, Politics, Governance 3 2750

Allen J, Cochrane A, 2007, "Beyond the territorial fix: regional assemblages, politics and power" Regional Studies 41 1161-1175

Allmendinger P, Chilla T, Sielker F, 2014, “Europeanizing territoriality - towards soft spaces?" Environment and Planning A 46 2703-2717

Bartholomew Review, 2015, Review of the ESRC Doctoral Training Centres Network (ESRC, Swindon)

Brickwood A, Brown N, 2005, Study of the English Higher Education Regional Association (HEFCE, Bristol)

Bristow G, 2005, “Everyone's a 'winner': problematising the discourse of regional competitiveness" Journal of Economic Geography 5 285-304

Charles D, Benneworth P, 2001, The Regional Mission - The Regional Contribution of Higher Education. The National Report (Universities UK/HEFCE, London)

Department for Business, Innovation and Skills, 2010, Local Growth - Realising Every Place's Potential (The Stationary Office, London)

Department for Business, Innovation and Skills, 2011, Innovation and Research Strategy for Growth (The Stationary Office, London)

Department for Education and Skills, 2003, The Future of Higher Education (The Stationary Office, London) 
Department of Trade and Industry, Department for Education and Skills, 2001, Opportunity for All in a World of Change: A White Paper on Enterprise, Skills and Innovation (The Stationary Office, London)

Fazackerly A, 2012, "Concentrating research funding on top universities threatens smaller institutions", The Guardian [Online], 5 November http://www.theguardian.com/education/2012/nov/05/research-fundingconcentrated-top-universities

Findlay AM, King R, Smith FM, Geddes A, Skeldon R, 2012, "World class? An investigation of globalisation, difference and international student mobility" Transactions of the Institute of British Geographers 37 118-131

Goddard J, Vallance P, 2013, The University and the City (Routledge, London)

Gunn A, Mintrom M, 2013, "Global university alliances and the creation of collaborative advantage" Journal of Higher Education Policy and Management 35 179-192

GW4, 2013, "South West research intensive universities join forces for new collaboration", 24 January, http://gw4.ac.uk/south-west-research-intensive-universities-join-forcesfor-new-collaboration

Harrison J, 2007, "From competitive regions to competitive city-regions: a new orthodoxy, but some old mistakes" Journal of Economic Geography 7 311-332

Harrison J, 2010, “Networks of connectivity, territorial fragmentation, uneven development: the new politics of city regionalism" Political Geography 29 17-27

Harrison J, 2013, "Configuring the new 'regional world': on being caught between territory and networks" Regional Studies 47 55-74

Harrison J, Smith DP, Kinton C, 2015, The New Regionalisation of UK Higher Education http://www.lboro.ac.uk/enterprise/regionalisation 
Higher Education Funding Council for England (2015) Recurrent Grants for 2015-16 (HEFCE, London)

Heley J, 2013, "Soft spaces, fuzzy boundaries and spatial governance in post-devolution Wales" International Journal of Urban and Regional Research 37 1325-1348

Jöns H, Hoyler M, 2013, "Global geographies of higher education: The perspective of world university rankings" Geoforum 46 45-59

Jump P, 2013, "Research heavyweights deny 'ganging up'", Times Higher Education, 9 May http://www.timeshighereducation.co.uk/news/research-heavyweights-denyganging-up/2003702.article

Kitagawa F, 2009, "Creating critical mass of research excellence in the region: the case of Scottish research pooling initiatives" European Planning Studies 17 487-495

Kitagawa F, 2010, "Pooling resources for excellence and relevance: an evolution of universities as multi-scalar network organisations" Minerva 48 169-187

MacLeod G, Jones M, 2007, "Territorial, scalar, networked, connected: in what sense a 'regional world'?" Regional Studies 41 1177-1191

Massey D, 1984, Spatial Divisions of Labour: Social Structures and the Geography of Production (Macmillan, Basingstoke)

Northern Way Steering Group, 2005, Action Plan (Northern Way Steering Group, Newcastle)

Pike A, Tomaney J, 2009, "The state and uneven development: the governance of economic development in England in the post-devolution UK" Cambridge Journal of Regions, Economy and Society 2 13-34

Roberts G, 2002, SET for Success - The Supply of People with Science, Technology, Engineering and Mathematics Skills (The Stationary Office, London) 
Sohn C, Reitel B, Walther O, 2009, "Cross-border metropolitan integration in Europe: the case of Luxembourg, Basel, and Geneva" Environment and Planning C 27 922-939

Smith DP (2009) "'Student geographies', urban restructuring, and the expansion of higher education" Environment and Planning A 41 1795-1804

Town and Country Planning Association, 2005, Smart Growth - The Midlands Way (Conference Flyer), Coventry, 2 March

University of Southampton, 2013, "New consortium positions UK's leading science universities on the global stage", 13 May, http://www.southampton.ac.uk/mediacentre/news/2013/may/13_81.shtml 


\section{FIGURE CAPTIONS}

Figure 1: The Geography of UK Higher Education Research Consortia

Figure 2: The Geography of EPSRC Doctoral Training Centres

Figure 3: The Geography of ESRC Doctoral Training Centres

Figure 4: The Geography of BBSRC Doctoral Training Centres

Figure 5a: The Geography of AHRC Doctoral Training Centres

Figure 5b: The Geography of AHRC Doctoral Training Partnerships

Figure 6: The Geography of NERC Doctoral Training Centres 





